\title{
Seronga - Para-ecologist Meshack Kwamovo
}

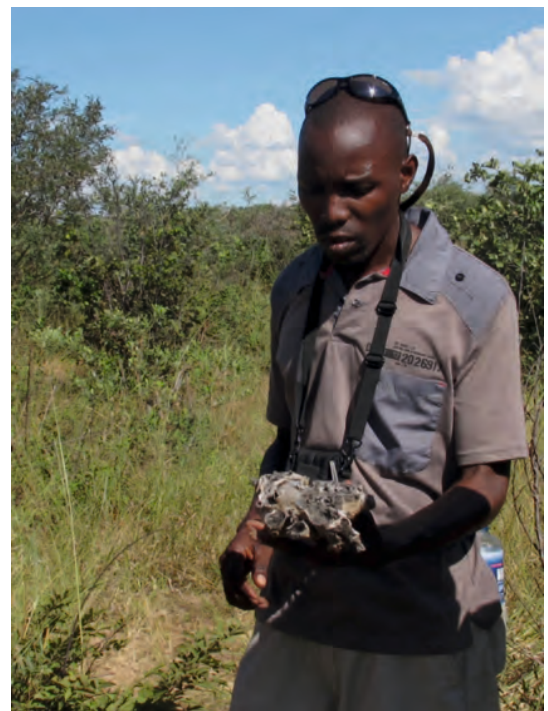

Fig. 1: Meshack Kwamovo (photo: U. Schmiedel).

I am Meshack Kwamovo (Fig. 1), born and raised in the Seronga village, Okavango sub-region, in the north-west part of Botswana. Seronga is situated where the Okavango River expands into many channels, lagoons, floodplains and islands, which are known as the Okavango Delta.

Seronga is a small village with a population estimated to be about 3000 people. The inhabitants belong to the following four tribal groups: Bayei, which is my tribal group, Hambukushu, Bakgalagadi and Basarwa. I speak the national language, Setswana, and English and can understand and speak Humbukushu and Sekgalagadi, the latter not fluent though.

Before I worked for the TFO project, from October 2011 till at present, I was trained on the job at the Wilderness Safaris Company as a safari lodge manager for three years (2002 until 2004). I also volunteered as a trustee for the Okavango Community Trust for four years (1998 until 2001), where I worked as the Board Secretary. I also worked as an assistant Professional Safari Guide for four years at the Um-vuvu camp (2007 until 2011). This camp is situated 12 kilometres south-east of Seronga village.

Within the TFO project, I assist researchers and also do some of the work on

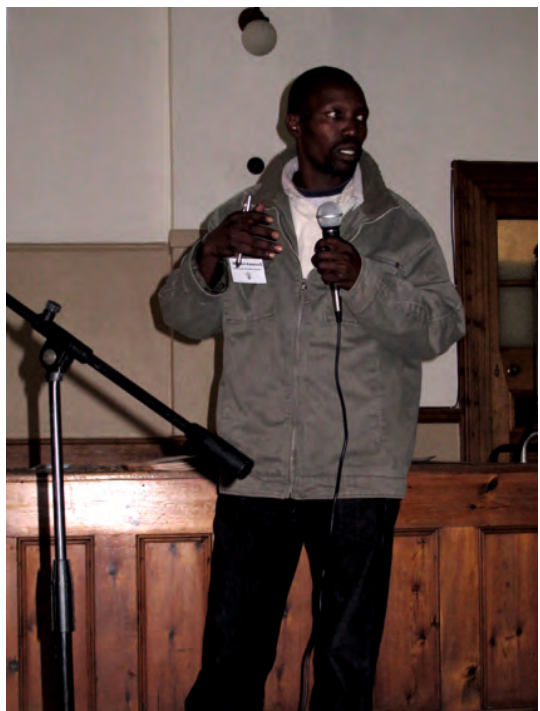

Fig. 2: Meshack Kwamovo giving an oral presentation at the Arid Zone Ecology Forum in Worcester, 2011 (photo: U. Schmiedel).

their behalf when they are not here, for example, taking some soil samples, doing yield measurements and taking weather records. Apart from that I help to organize accommodation for them, arrange workshops and community meetings as well as conduct workshops.

The one lesson I learnt from working with TFO is that, working at the same time

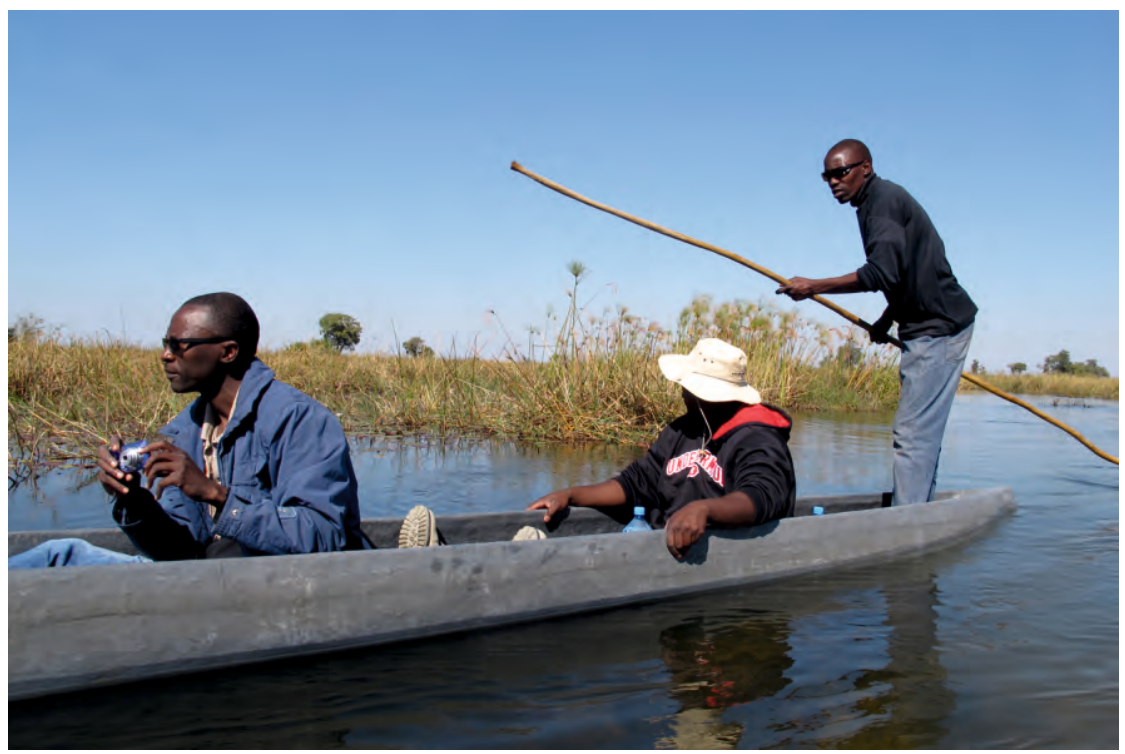

Fig. 3: Meshack Kwamovo as a poler in the Kavango Delta (photo: U. Schmiedel). with two different institutions who have different systems in how they operate, makes things sometimes complicated and confusing. Due to long communication channels it is hard to get materials needed in order to carry out work easily and on time. Resolutions are hardly ever made, however I learnt to work with difficult conditions.

I have collected field experience such as GPS device use, use of digital cameras and also learnt the importance of networking, report writing and I am improving on my flora and fauna knowledge. I am also able to build my confidence when it comes to addressing groups of people.

\section{Acknowledgements}

The project was funded by the BMBF (The Future Okavango project). For details see authors' general acknowledgements in this volume. more practice on computer operations. I

Responsible author: M. Kwamovo 
